OPEN ACCESS

Edited by:

Nader Kim El-Mallawany, Baylor College of Medicine,

United States

Reviewed by:

Chris A. Rees,

Boston Children's Hospital and

Harvard Medical School,

United States

Allison Mari Dering-Anderson,

University of Nebraska Medical

Center, United States

Erin C. Peckham-Gregory,

Baylor College of Medicine,

United States

*Correspondence:

Fred M. Ssewamala

fms1@wustl.edu

Specialty section:

This article was submitted to

Children and Health,

a section of the journal

Frontiers in Public Health

Received: 14 January 2020

Accepted: 09 July 2020

Published: 14 August 2020

Citation:

Katumba RGN, Sensoy Bahar O, Johnson KJ and Ssewamala FM

(2020) Cancer in Youth Living With HIV

(YLWHIV): A Narrative Review of the Access to Oncological Services Among YLWHIV and the Role of Economic Strengthening in Child Health. Front. Public Health 8:409.

doi: 10.3389/fpubh.2020.00409

\section{Cancer in Youth Living With HIV (YLWHIV): A Narrative Review of the Access to Oncological Services Among YLWHIV and the Role of Economic Strengthening in Child Health}

\author{
Ruth G. N. Katumba ${ }^{1}$, Ozge Sensoy Bahar ${ }^{2}$, Kimberly J. Johnson ${ }^{2}$ and \\ Fred M. Ssewamala ${ }^{2 *}$ \\ ${ }^{1}$ School of Medicine, Washington University in St. Louis, St. Louis, MO, United States, ${ }^{2}$ Brown School, Washington \\ University in St. Louis, St. Louis, MO, United States
}

Youth Living with HIV/AIDS (YLWHIV) have a higher risk of developing immunodeficiency related illnesses including certain cancers than their general population counterparts of the same age. This narrative review of current available literature describes factors associated with pediatric access to oncological services, and the role economic strengthening could play in improving health outcomes for this vulnerable population. Findings suggest that both HIV-infected and -uninfected children living in low and middle-income countries struggle with access and adherence to cancer treatment and care. Cost of treatment is a major barrier to access and adherence. Asset-building savings programs may increase financial security and subsequently result in better health outcomes although they have not been utilized to improve access to cancer treatment.

Keywords: HIV/AIDS, malignancies, youth, sub-Saharan Africa, access to cancer services, economic strengthening

\section{INTRODUCTION}

The HIV/AIDS pandemic continues to pose a significant threat to global public health (1). According to the World Health Organization (WHO), 37.9 million people were living with HIV at the end of 2018, with 1.7 million new infections within that year globally (2). Furthermore, 940,000 people died from HIV-related causes globally in 2017 (2). Africa is the most affected region, with more than two thirds of the total new HIV infections and people living with HIV worldwide $(2,3)$.

Youth (0-24 years) are greatly affected by the HIV pandemic. This can be explained by their diverse risk factors whereby children can acquire HIV from their infected mothers during birth and postnatally from breast feeding while 15 to 24 -year-olds fall within a young adult category for which unsafe sex is the main risk factor for HIV contraction $(4,5)$. In both 2016 and 2018, youth aged 13-24 made up $21 \%$ of all new HIV diagnoses in the United States (U.S.) $(6,7)$. Additionally, WHO global health estimates from 2016 show that for females aged 10-14 years, HIV/AIDS was the leading cause of mortality while for their male counterparts, HIV/AIDS was the leading cause of infection-related death and third leading cause of death overall (after road injuries and drowning) (6). Furthermore, for youth living with HIV (YLWHIV); defined as youth under the age of 18 years, AIDS-related illnesses are still among the leading causes of mortality (6). Africa is home to most of 
the affected children whereby 58\% (1.04 million) are from Eastern and Southern Africa and 29\% (0.5 million) are from Western and Central Africa (8).

AIDS-related illnesses contributing to mortality among people living with HIV are thought to develop as a result of HIV effects on patients' immune systems (9). Examples of these illnesses are opportunistic coinfections (e.g., tuberculosis, toxoplasmosis, pneumocystis pneumonia) and some cancers (10). Regarding the latter, people living with HIV have a significantly higher risk of developing certain cancers than the general population of the same age (11). HIV infection among cancer patients is also associated with a significantly higher risk of dying from that cancer (11).

HIV-associated cancer risk and survival among YLWHIV has changed over time with the advent of increased access to and uptake of antiretroviral therapy (ART) (8). Prior to ART, cancer risks were reported at $>40$-fold higher in HIV positive youth (1), with the greatest risks for Kaposi's sarcoma (KS), Non-Hodgkin's lymphoma, and Burkitt's lymphoma (12-15). In the post-ART era, 4 to 14 -fold higher pediatric cancer risks have been reported in South Africa $(8,16)$. It is important to highlight that despite the increased access and effectiveness of ART among people living with HIV, cancer survival among YLWHIV is low in low-resource settings and cancer risk is still higher for children that start ART at an older age and/or who have greater immunosuppression than for those who start ART a younger age and/or who have less immunosuppression (16).

The WHO highlights the importance of early diagnosis for all pediatric cancers and access to treatment for children and adolescents with cancer for better survival (17). Proper access to quality care can result in better prognosis (18). Evidence from high income countries indicates that with proper access to quality care, more than $80 \%$ of children with cancer can survive and live full and healthy lives (19-21). This paper provides a narrative review of the factors associated with youth pediatric access to oncological services; and the potential role of economic strengthening can play in improving health outcomes for this population and for all children in low resource settings.

\section{METHODS}

This narrative review has the two primary objectives (1) examining access to oncological treatment services among children and (2) discussing the potential role of economic strengthening programs in improving health outcomes for YLWHIV who develop cancers.

\section{Search Strategy}

Articles were obtained through a comprehensive search of MEDLINE, CINAHL, CINAHL Plus, Ovid, PsycINFO, Academic Search Complete, Global Health, SocINDEX, SOCIndex with Full Text, and EBSCOhost's Clinical and Academic Collections using search terms in Table 1. This search was carried out and reviewed for eligibility by two research assistants. These articles were supplemented through Google scholar and references from key articles.

\section{Inclusion/Exclusion Criteria}

Out of more than 100 articles and internet sources identified from the search conducted over a period of $\sim 4$ months, material from 73 sources that provided information related to the papers' objectives was included. These articles include those obtained during the search (43) and supplemented sources (30) obtained from Google scholar searches and reference lists from included articles.

\section{Global Burden of Cancers Among Youth Living With HIV}

While most YLWHIV live in SSA, cancer studies from this region are scarce. The number of YLWHIV who develop a malignancy in SSA is poorly defined and available data generally focuses on younger children ( $<16$ years). HIV-related cancer surveillance is further hampered by lack of systematic collection of cancer diagnoses in HIV cohorts and absence of HIV status in available local cancer registries.

Of an estimated 429,000 expected new cases of childhood cancer each year, almost 90\% will occur in LMICs and over $80 \%$ of the global burden of pediatric cancer mortality is in LMIC $(22,23)$. A review of the literature demonstrated that the burden of cancers and cancer types differs greatly between high income countries and low- to lower-middle-income countries (LMICs) $(22,24)$ as well as by region $(24-26)$. Additionally, Ward et al. estimated that over 3 million cases of pediatric cancer will go undiagnosed between 2015 and 2030 (22) and 56\% of cases in East Africa will be undiagnosed compared to only 3\% in North America (22).

Studies from lower income countries in the pre-ART era demonstrated a $>40$-fold higher risk of developing cancer in HIV-infected youth compared to their general population counterparts, with Kaposi sarcoma (KS), NonHodgkin's lymphoma and specifically Burkitt's lymphoma having the greatest relative risks (12-15). While the introduction of and increased access to ART increased survival, studies from South Africa in the post-ART era still find a higher risk (between 14 and 14 times) of developing cancer among YLWHIV (8, 16). Additionally, a retrospective study in South Africa found that HIV-positive children with cancer were generally younger (average age 6 years) compared to HIV-negative patients with cancer (average age 6.5 years) $(25,27)$. This study also reported higher mortality among HIV-positive children and that the ratio of living children who were cancer-free to the total of children in the respective category, was significantly smaller among HIVpositive participants. Studies from Malawi on Kaposi sarcoma reported that YLWHIV in the post-ART era are still at a high risk for the disease $(28,29)$.

\section{Access to Oncological Treatment Services for Youth}

YLWHIV generally have poor survival despite chemotherapy compared to uninfected peers, mainly due to patients' severe immunodeficiency $(21,30)$. However, survival may be moderated by differences in access to therapeutic options between HIVpositive and HIV-negative children with cancer. Proper access to quality care can result in better prognosis as well as minimal side or late effects associated with disease and treatment, respectively, 
TABLE 1 | Search terms and key words used in the literature search.

\begin{tabular}{|c|c|c|c|c|}
\hline Youth terms & HIV/AIDS terms & Cancer terms & Treatment/Treatment delay terms & Epidemiology terms \\
\hline $\begin{array}{l}\text { Pediatric } \\
\text { Pediatrics } \\
\text { Pediatric* } \\
\text { Children } \\
\text { Kids Adolescents Youth } \\
\text { Kid } \\
\text { Adolescent Childhood } \\
\text { Young adults-people teens } \\
\text { and people in early twenties } \\
\text { Teens } \\
\text { Youngster } \\
\text { Boy } \\
\text { Girl } \\
\text { Infant }\end{array}$ & $\begin{array}{l}\text { HIV } \\
\text { AIDS } \\
\text { Human immunodeficiency virus } \\
\text { Acquired immunodeficiency } \\
\text { syndrome } \\
\text { Persons living with HIV } \\
\text { Persons living with AIDS } \\
\text { People living with HIV } \\
\text { People living with AIDS } \\
\text { Persons living with HIV/AIDS } \\
\text { People living with HIV/AIDS } \\
\text { Viral suppression } \\
\text { Virally suppressed } \\
\text { *HAART } \\
{ }^{*} \text { ART } \\
\text { *Pediatric ART } \\
\text { cART }\end{array}$ & $\begin{array}{l}\text { Cancer } \\
\text { Cancers } \\
\text { Malignancies } \\
\text { Malignant } \\
\text { Malignancy } \\
\text { Tumor } \\
\text { Tumors } \\
\text { Neoplasm } \\
\text { Neoplasms } \\
\text { Carcinoma } \\
\text { Carcinomas } \\
\text { Oncology } \\
\text { Malignant tumors } \\
\text { Kaposi sarcoma } \\
\text { Non-Hodgkin's lymphoma } \\
\text { Burkitt's lymphoma } \\
\text { Leiomyosarcoma } \\
\text { Cervical cancer } \\
\text { Lymphoma } \\
\text { HPV-related cancers } \\
\text { HIV-related cancers } \\
\text { Lymphoproliferative disorder* }\end{array}$ & 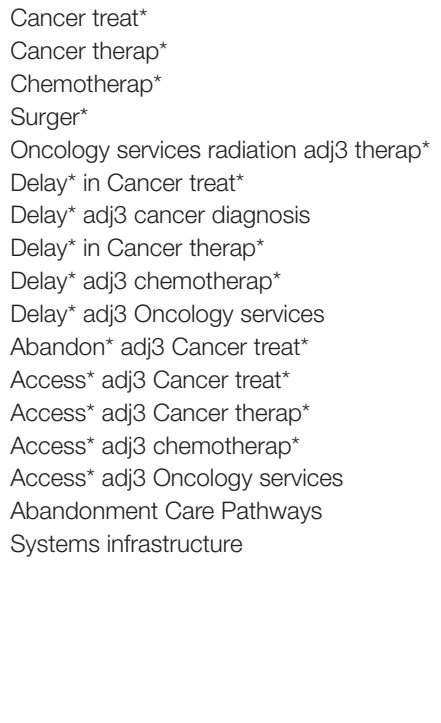 & $\begin{array}{l}\text { Epidemiology } \\
\text { Incidence } \\
\text { Cumulative incidence } \\
\text { Prevalence } \\
\text { Survival analysis } \\
\text { Survival rates } \\
\text { Kaplan Meier } \\
\text { Incidence rates } \\
\text { Risk ratio } \\
\text { Relative risk } \\
\text { Rate ratio } \\
\text { Incidence density } \\
\text { Prevalence ratio } \\
\text { Standardized incidence rate }\end{array}$ \\
\hline
\end{tabular}

whereby younger YLWHIV who access care earlier and at lower levels of immunosuppression may have better tolerance and/or responses to necessary high doses of chemotherapy $(18,31)$. Evidence from high income countries indicates that with proper access to quality care, more than $80 \%$ of children with cancer can survive and live full and healthy lives (32). A study in South Africa indicated that YLWHIV receiving antiretroviral therapy (ART) have a substantially lower risk of developing cancer than those who are not on ART [hazard ratio (HR) 0.29] (16). Biggar et al. also found that survival among YLWHIV with cancer was greater for those treated with ART and chemotherapy (33). Yet, numerous children (both HIV-infected and uninfected) in LMICs continue to struggle with access and adherence to care, contributing to childhood cancer deaths in low resource settings globally (17). Hence, timely access to quality healthcare is an important public health concern.

Access to pediatric oncology services is defined in terms of delay, waiting time, as well as treatment adherence and abandonment. Delay is further categorized as patient/parent delay, health care system delay, physician/health system delay, referral delay, diagnosis delay, treatment delay, lag time, and ultimately, total delay (defined as the time from onset of symptoms to initiation of therapy) $(18,34)$. Total delay in childhood cancer is a major contributor to cancer-related death among children worldwide and many factors contribute to this delay $(34,35)$. Overall, health system-related factors have been found to contribute more significantly to lag time than parent delays $(33,34,36)$.

\section{Factors Associated With Delay and Abandonment Among Youth Living in LMICs}

Several barriers exist to accessing cancer treatment among children and consequently contribute to delay (see Figure 1).
As children typically depend on parents/guardians to access health services, individual-level factors are grouped along with interpersonal factors since their influence is ultimately evaluated on an interpersonal basis. Regarding structural factors, most LMICs have only few established cancer centers, whereby cancer services are usually obtained from general surgical or medical departments in non-specialized hospitals (37). These are district or regional hospitals, with little or no information about quantity or quality of the services provided (37). They also typically exist in large urban areas, whereas most of the population lives in rural areas. These hospitals often lack reliable routine pathology, imaging, oncology nursing, and specialized pharmacy departments or have units that offer low quality service and insufficiently trained personnel. This lack or limited scope of pathology services is a major challenge in several SSA countries where there is typically one pathologist for every 500,000 to 1 million people (37).

Lack of affordable local treatments options are amplified by long distances to treatment centers and transportation difficulties $(38,39)$. Clinical care and transportation costs also play major roles in patient delay. In both Uganda and western Kenya, nearly all guardians rely on public transportation to reach the cancer referral centers, yet transportation costs are high and travel time is long (40). Lack of funds is a critical factor for treatment abandonment $(38,40)$. Furthermore, the search for an accurate diagnosis and effective treatment was resource-intensive and complicated for many guardians and generally involved multiple visits to different health facilities and care providers (40). Unfortunately, many children remained undiagnosed or were inappropriately treated before getting to cancer referral centers. Studies highlight mismanagement of cancer cases at lower level facilities as a key weakness in health care systems which contributes to late stage of presentation and poor outcomes 


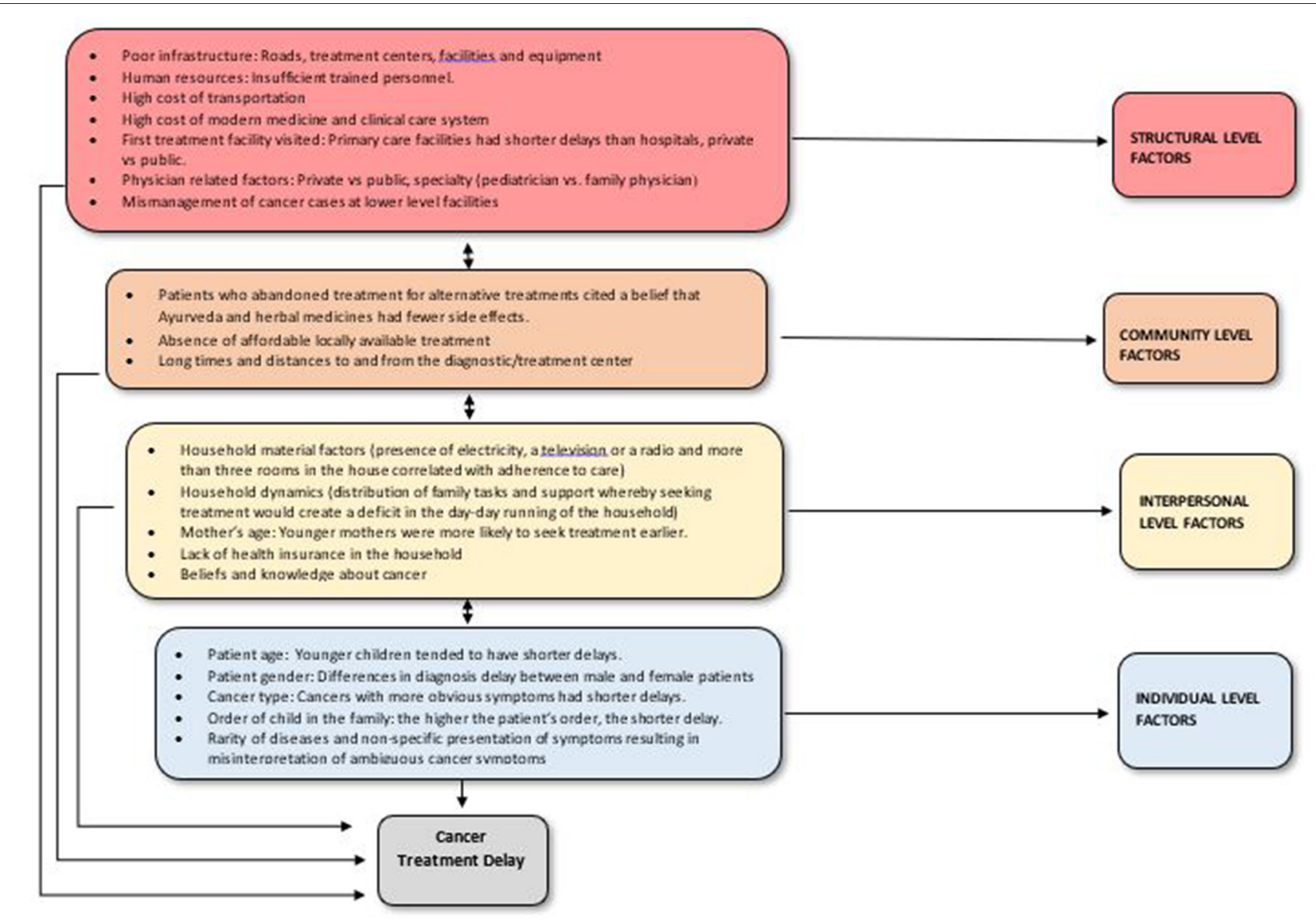

FIGURE 1 | Factors associated with total delay and abandonment of cancer care among children and youth in LMICs.

among children (40). Relatedly, parents who sought alternative sources of care had perceptions of unsatisfactory management by respective health facilities and a lack of confidence in health care systems (39). Alternative treatments were also sought due to the cost of modern medicine and the belief that alternative medicine had fewer side effects (41).

Caregiver education and profession also affect access to cancer treatment services. In a study in Argentina, retinoblastoma patients whose parents had an elementary education or lower had a greater risk of longer patient delay [odds ratio $(\mathrm{OR})=6.34$ ] (18). In Mexico, children whose parents had the lowest level of education had longer delays in diagnosis $(\mathrm{OR}=1.4$ for fathers and 1.5 for mothers). While there were no significant associations with father's profession, the lag time for mothers with a "blue collar" profession was greater than for both housewives or mothers with academic professions (8.5-13.5 weeks vs. 5.5-6 weeks) (42). Conversely, in Nigeria, children of parents with a higher level of education, who favor private hospitals over public ones, suffered longer diagnosis delays despite being more economically empowered (43).

In a study conducted in Latin America, Asia and the Caribbean, household assets correlated with adherence to care
(41). In Uganda, household dynamics (e.g., distribution of family tasks, guardian's role as caretaker, and social support) contributed to patient/parent delay whereby seeking treatment created a deficit in the day-to-day running of households (40). Consequently, parents without a support system for other children in the home and/or someone to take over their tasks had longer delay. Parent delay among Ugandan guardians was also influenced by guardians' beliefs about the curability of cancer, health system delay, and by guardians' perceptions of cancer as a contagious disease (41). Hence, understanding the role of cultural/community context when describing barriers and designing interventions is essential.

A study in Israel, a high-income country, also observed a significant positive correlation between child's age at diagnosis and lag time whereby the lag time increased as the child's age increased (44). Diagnosis delay was shortest for children between the ages of 0-2 years despite no significant differences in histopathology, grade or location of tumors, and parental persistence (number of consultations before diagnosis) across age groups. The association with child's age was explained by the expectation that younger children have closer parental supervision, which may facilitate the recognition of symptoms 
and signs, as opposed to older children and adolescents who more often initiate the recognition of signs and symptoms themselves. Adolescents may also be more likely to undervalue symptoms and delay calling attention to them, resulting in increased delays. Moreover, if the child was the oldest, the parent's delay was shorter, underlying birth order as a critical factor. Patients with younger mothers were more likely to seek treatment earlier vs. those with older mothers. This was attributed to younger mothers having less experience in taking care of children and therefore being more likely to seek medical attention earlier (39).

Cancer-related factors such as the cancer type, symptoms, stage, and tumor site/location also contribute to delays. Cancer type was significantly associated with delayed time to diagnosis especially when comparing different groups of cancers to leukemia, an effect which persisted even after adjusting for age, sex, and race (40). The timely diagnosis of cancer in children was found to be further complicated by the rarity of the disease and the non-specific presentation of symptoms as well as misinterpretation of ambiguous cancer symptoms by patients, parents, and physicians (18). Patients with abnormal masses had shorter diagnosis delays, patients with rare symptoms had shorter parent delay, fast-growing tumors had shorter delays than slow-growing ones and patients who presented with pain as the primary symptom had significantly longer total delay and physician delay $(35,38)$. Patients with disseminated disease also had significantly longer delays compared to patients with localized disease (45).

The type of physician seen first (private vs. public), physician specialty (pediatrician vs. family physician), type of facility (private vs. public), health insurance, and the fear of visiting tertiary health care institutions also contributed to delays among children with suspected cancers (43). When the first health consultant was a private physician, the lag time was shorter than when it was a physician at a public clinic; and both lag time and physician delay were shorter among children seen by pediatricians compared to those seen by family physicians or other specialists (44). Finally, a lack of health insurance combined with the initial use of alternative medicine was also significantly associated with longer patient delays (36).

This review could not identify studies that compared access to oncological services between HIV-positive and negative children. Yet, two U.S.-based studies focused on adults demonstrated that people living with HIV were less likely to receive cancer treatment and that the delay between diagnosis to treatment was also significantly longer than that of HIV negative individuals (41). The lack of resources and varying treatment availability within and across different regions makes the evaluation of cancer in the pediatric HIV population particularly challenging. The weaknesses in health care infrastructure for diagnosing cancers along with limited epidemiological expertise in LMICs, especially in SSA also result in sparse data on the burden of AIDS defining malignancies and other associated cancers (45).

\section{Current Interventions and the Potential Role of Socio-Economic Empowerment in Improving Access}

Children with cancer in LMICs not only experience multiple barriers to treatment access, but they also have lower childhood cancer survival rates $(15,46)$. The reasons for the low survival rates are multiple, interrelated, and associated with factors that affect access to treatment services, treatment adherence as well as abandonment. The small number of facilities providing cancer treatment and supportive services along with lack of welltrained multidisciplinary staff are further aggravated by poor nutritional status of children and late patient presentation to the health centers and/or specialized personnel (47). Hence, further development and evaluation of interventions aimed at improving access to oncological services for youth is required.

Despite improvement in outcomes for pediatric cancer patients in LMICs, many challenges persist. Interventions including targeted health education of guardians on the importance of early care for children's illnesses as well as advocacy and education of health workers to facilitate the identification of early warning signs of childhood cancer and foster timely referral and diagnosis are crucial for patient survival (40). Parent support groups also offer vital support in providing medications, housing and psychosocial support (48). Additionally, the establishment of cancer centers and "twinning" partnerships with institutions from high-income countries in many LMICs, especially in SSA countries, have led to infrastructure improvement as well as personnel and facilitycapability to provide proper cancer treatment and care $(47,48)$. Twinning partnerships occur across multiple levels including the local public sector, private-sector and international organizations and include education, care-linkage, mentorship (e.g., regular online conferences in international partnerships), and in some cases, funding (47).

Similarly, regional collaborations between cancer centers have driven progress in pediatric access to treatment and survival (49). Developing national protocols and guidelines for treatment that account for local contexts (e.g., unavailability of certain drugs or treatment modalities) is also another important step (47). For instance, the committee for Pediatric Oncology in Developing Countries published treatment guidelines for children with common and curable cancers (including YLWHIV) $(49,50)$. Other considerations include improving supportive care services, infection control programs (especially opportunistic infections among YLWHIV) and nutritional support benefits (47).

Developing sustainable and contextually relevant interventions, especially in resource-poor settings is imperative. While current interventions are vital and have resulted in increased access and government involvement in oncological care, socio-economic factors, and treatment-related costs play a significant role in the cancer-care pathway (40). Hence, interventions increasing the ability of families with young cancer patients to engage with the healthcare system may lead to better health outcomes.

This economic empowerment can be achieved using an assetbased model, which is an integrated approach for building human, social, and economic capital $(51,52)$. The asset theory posits that asset building (e.g., savings, educational opportunities, and economic opportunities in the form of small businesses or income generating activities) has important long-term positive benefits $(53,54)$. Asset theorists have described these as "asset effects" (55) which include acquiring a sense of economic 
security, self-confidence, hope, and responsibility (56). This empowerment could facilitate families' access to formal financial products (e.g., savings and credit lines) to meet the healthcare needs such as treatment for HIV and cancer, foster adherence and consequently improve health outcomes (57).

People living in poverty acquire personal financial resources either through savings or loans (58). However, if the latter are not managed well, they can increase the financial burden on recipients rather than facilitate improved quality of life (59). Therefore, saving programs would be the better option to address disparities in treatment access and help families with children suffering from cancer.

Asset-based development through savings interventions has been used with success to improve quality of life. For example, the Suubi projects (Hope in Luganda, the local language in the region) in the Greater Masaka region in Uganda have employed an asset development approach in working with orphaned and vulnerable children in poverty -including YLWHIV, which among other components, involve setting up a Child Savings Account (CSA) $(58,59)$. CSA is a matched savings account held in the child's name in an officially registered financial institution or bank (60) and for youth and their families to use for school-related expenses, post-primary education, and in the case of YLWHIV for medical expenses, or to start small family business development projects $(53,60)$. Tested using randomized controlled trials, results indicate that this program is effective in reducing children's economic barriers to attend school, supporting the argument that such programs can address family-level and child poverty, which could in turn improve health outcomes. More specifically for YLWHIV, in a large sample of Ugandan adolescents between the ages of 10 and 16 years and living with HIV, the intervention was found to significantly improve viral suppression, the primary marker of ART adherence $(61,62)$. It is possible that the promotion of financial stability may have addressed transport costs and food security, both of which are factors identified as barriers to ART adherence (63-66). Given these results, economic empowerment interventions may also effectively address barriers to cancer treatment and care.

\section{Next Steps}

Capacity building activities across all levels of health care systems are key to the care and treatment of children with cancer in LMICs-both with and without HIV infection. This approach requires collaborative work based on local stakeholder and government buy-in in order to set the priorities because they know best what they need and is feasible. Strengthening and expanding comprehensive pediatric cancer registries, especially in SSA will provide opportunities for research and innovative treatment approaches to improve survival. Collaboration between new and existing cancer and HIV registries for children and youth can further facilitate this process. Larger longitudinal studies are also needed to determine incidence of cancers in HIV-positive and HIV-negative children to better characterize the association between seropositivity and cancer.
Established HIV-care systems and mechanisms at both local and regional levels should be utilized to provide cancer diagnosis and linkage to treatment services. Setting up centralized cancer treatment centers, partnering with established cancer units, establishing locally adapted protocols, and getting financial support from the government are all helpful in reducing treatment abandonment (41). Careful consultation is also required between the different subspecialties involved in the care of these children, including the multidisciplinary HIV team, infectious disease, and oncology subspecialists, so that decisions about cancer treatment are made in the context of ART, and consider the treatment required for other HIV-associated disorders and patient quality of life. As cancer becomes more frequent in both people living with HIV and YLWHIV, physicians need to better understand and agree on when to treat, when to palliate, and, with treatment, how to minimize complications while achieving remission.

Research on diagnosis delays in childhood cancer is also important. There is also a need for more studies to investigate the potential impact of delays on prognosis outcomes. Future studies should study access to oncological services among YLWHIV, a high-risk group for pediatric cancer. Examining the impact of patient and provider/healthcare-system delays on disease severity and prognosis as well as the factors influencing these delays would inform effective policies and programs aimed at eliminating obstacles in the cancer-care pathway for youth with cancer.

Finally, better strategies to reduce treatment abandonment and improve survival in childhood cancer in the developing world are still needed. Increasing awareness of childhood cancers and addressing structural and socio-economic factors impacting access to cancer treatment services can be considered as potential strategies. Moreover, complementing current structural interventions with the adoption of asset-based models to improve access and adherence to oncological treatment could be vital to pediatric cancer patients, especially YLWHIV.

\section{CONCLUSION}

Pediatric cancers among youth are rare but serious lifethreatening conditions. YLWHIV are particularly at a higher risk of developing and dying from cancer than their general population counterparts. Pediatric cancer patients have limited access to oncological services and healthsystem-related factors play a major role in delayed access to treatment. Failure to meet treatment costs is a major contributor to treatment abandonment. This paper discussed the potential role of socio-economic strengthening and provided evidence that asset-building savings programs can increase financial security and subsequently result in better health outcomes. Further exploration, development, and evaluation of interventions to address gaps and challenges to access to oncological services among YLWHIV and all children are crucial next steps. 


\section{AUTHOR CONTRIBUTIONS}

FS, OS, and KJ were principal investigators for the NIH funding. RK drafted the manuscript. OS, FS, and $\mathrm{KJ}$ reviewed and made substantive edits to the manuscript. All authors contributed to the article and approved the submitted version.

\section{REFERENCES}

1. WHO. HIV/AIDS. World Health Organization. (2018). Available online at: https://www.who.int/en/news-room/fact-sheets/detail/hiv-aids2 (accessed December 15, 2018).

2. WHO. HIV/AIDS. World Health Organization. (2018). Available online at: http://www.who.int/news-room/fact-sheets/detail/hiv-aids (accessed Auguest 12, 2018).

3. WHO. Number of people (all ages) living with HIV: Estimates by WHO region. World Health Organization. (2019). Available online at: https://apps. who.int/gho/data/view.main.22100WHO?lang=en (accessed June 3, 2020).

4. Avert. Prevention of Mother-to-Child Transmission (PMTCT) of HIV. Avert (2020). Available online at: https://www.avert.org/professionals/hivprogramming/prevention/prevention-mother-child\#: ssim:text=Prevention $\% 20$ of\%20mother\%2Dto\%2Dchild\%20transmission\%20(PMTCT) $\% 20$ programmes, throughout\%20pregnancy\%2C\%20labour\%20and \%20breastfeeding (accessed June 3, 2020).

5. Roser M, Ritchie H. HIV/AIDS. Our World in Data. (2020). Available online at: https://ourworldindata.org/hiv-aids (accessed June 3, 2020).

6. WHO. WHO | Causes of Death Among Adolescents. WHO (2018). Available online at: http://www.who.int/maternal_child_adolescent/data/ causes-death-adolescents/en/ (accessed September 19, 2018).

7. Centers for Disease Control and Prevention. HIV Surveillance Report. 2018 (Preliminary). Vol. 30 (2019). Available online at: http://www.cdc.gov/hiv/ library/reports/hiv-surveillance.html (accessed May 25, 2020)

8. Singh E, Naidu G, Davies MA, Bohlius J. HIV-associated malignancies in children. Curr Opin HIV AIDS. (2017) 12:77-83. doi: 10.1097/COH.0000000000000331

9. Pietrangelo A, Nall R. "HIV and Cancer: Risks, Types, and Treatment Options". (2018). Available online at: https://www.healthline.com/health/hiv-aids/hivand-cancer (accessed May 25, 2020)

10. AIDSinfo. HIV Children Adolescents | Understanding HIV/AIDS | AIDSinfo. U.S. Department of Health an Human Services (2018). Available online at: https:/aidsinfo.nih.gov/understanding-hiv-aids/fact- sheets/25/82/hiv-andchildren-and-adolescents (accessed Auguest 12, 2018).

11. Coghill AE, Pfeiffer RM, Shiels MS, Engels EA. Excess mortality among hiv-infected individuals with cancer in the United States. Cancer Epidemiol Biomarkers Prev. (2017) 26:1027-33. doi: 10.1158/1055-9965.EPI-16-0964

12. Parkin DM, Stefan C. Editorial: childhood cancer in sub-Saharan Africa. Ecancermedicalscience. (2017) 11:ed69. doi: 10.3332/ecancer.2017.ed69

13. Simard EP, Shiels MS, Bhatia K, Engels EA. Long-term cancer risk among people diagnosed with AIDS during childhood. Cancer Epidemiol Biomark Prev. (2012) 21:148-54. doi: 10.1158/1055-9965.EPI-11-0823

14. Chen C-H, Chung C-Y, Wang L-H, Lin C, Lin H-L, Lin H-C. Risk of cancer among HIV-infected patients from a population-based nested casecontrol study: implications for cancer prevention. BMC Cancer. (2015) 15:133. doi: 10.1186/s12885-015-1099-y

15. Ziegler JL, Katongole-Mbidde E. Kaposi's Sarcoma in childhood: an analysis of 100 cases from Uganda relationship to HIV infection. Int $J$ Cancer. (1996) 65:200-2033. doi: 10.1002/(SICI)1097-0215(19960117)65:2<200::AID-IJC12>3.0.CO;2-H

16. Bohlius J, Maxwell N, Spoerri A, Wainwright R, Sawry S, Poole J, et al. Incidence of AIDS-defining and other cancers in HIV-positive children in South Africa. Pediatr Infect Dis J. (2016) 35:e164-70. doi: 10.1097/INF.0000000000001117

17. WHO. WHO | International Childhood Cancer Day: 15 February 2017. WHO (2017). Available online at: http://www.who.int/cancer/iccd 2017/en/ (accessed August 19, 2018).

\section{FUNDING}

This work was supported by National Cancer Institute (NCI) at National Institutes of Health. The funded research project, entitled Suubi4Cancer (NCI R21CA236531), focused on improving access to pediatric cancer services, and treatment adherence among children living with HIV/AIDS.

18. Dang-Tan T, Franco EL. Diagnosis delays in childhood cancer. Cancer. (2007) 110:703-13. doi: 10.1002/cncr.22849

19. Gupta S, Howard SC, Hunger SP, Antillon F, Metzger M, Israels T, et al. Treating childhood cancer in low- and middle-income countries. In: Disease Control Priorities. Vol. 3 (2018). Available online at: http://dcp-3.org/ chapter/900/treating-childhood-cancers-low-and-middle-income-countries (accessed June 3, 2020).

20. Howard SC, Zaidi A, Cao X, Weil O, Bey P, Patte C, et al. The my child matters programme: effect of public-private partnerships on pediatric cancer care in low-income and middle-income countries. Lancet Oncol. (2018) 19:e252-66. doi: 10.1016/S1470-2045(18)30123-2

21. Cancer. Survival Rates for Childhood Non-Hodgkin Lymphoma. Cancer (2020). Available online at: https://www.cancer.org/cancer/childhoodnon-hodgkin-lymphoma/detection-diagnosis-staging/survival-rates.html (accessed June 3, 2020).

22. Ward ZJ, Yeh JM, Bhakta N, Frazier AL, Atun F. Estimating the total incidence of global childhood cancer: a simulation-based analysis. Lancet Oncol. (2019) 20:483-93. doi: 10.1016/S1470-2045(18)30909-4

23. Bhakta N, Force LM, Allemani C, Atun R, Bray F, Coleman MP, et al. Childhood cancer burden: a review of global estimates. Lancet Oncol. (2019) 20:e42-53. doi: 10.1016/S1470-2045(18)30761-7

24. World Bank. International Agency for Research on Cancer (IARC) GLOBOCAN 2012: Estimated Cancer Incidence, Mortality and Prevalence Worldwide in 2012. WHO (2020). Available online at: http://globocan.iarc.fr/ Pages/age-specific_table_sel.aspx (accessed June 3, 2020).

25. The World Bank. Data by Country: Countries and Economies. World Bank (2020). Available online at: http://data.worldbank.org/country (accessed June $3,2020)$.

26. Rodriguez-Galindo C, Friedrich P, Alcasabas P, Antillon F, Banavali S, Castillo $\mathrm{L}$, et al. Toward the cure of all children with cancer through collaborative efforts: pediatric oncology as a global challenge. J Clin Oncol. (2015) 33:306573. doi: 10.1200/JCO.2014.60.6376

27. Stefan DC, Stones DK. Children with cancer and HIV infection: what is different about them? J Pediatr Hematol Oncol. (2013) 35:590-6. doi: 10.1097/MPH.0b013e3182913e6a

28. Sinfield RL, Molyneux EM, Banda K, Borgstein E, Broadhead R, Hesseling $\mathrm{P}$, et al. Spectrum and presentation of pediatric malignancies in the HIV era experience from Blantyre, Malawi, 1998-2003. Pediatr Blood Cancer. (2007) 48:515-20. doi: 10.1002/pbc.20917

29. Orem J, Otieno MW, Remick SC. AIDS-associated cancer in developing nations. Curr Opin Oncol. (2004) 16:468-76. doi: 10.1097/00001622-200409000-00010

30. National Cancer Institute. Cancer in Children and Adolescents - National Cancer Institute. NCI. (2017). Available online at: https://www.cancer. gov/types/childhood-cancers/child-adolescent-cancers-fact-sheet (accessed August 16, 2018).

31. Whittington E. Kids and adults: what's the difference? Cure Today. (2008). Available online at: https://www.curetoday.com/publications/cure/2008/ summer2008/kids-and-adults- whats- the-difference\#: $\mid$ sim:text=Indeed $\% 2 \mathrm{C}$ \%20childhood\%20cancer\%20survivors\%20are,Matthay (accessed June 3, 2020).

32. Gupta S, Howard S, Hunger S, Antillon F, Metzger M, Israels T, et al. Treating childhood cancers in low- middle-income countries. In: Gelband H, Jha P, Sankaranarayanan R, Horton S, editors. Disease Control Priorities. 3rd ed. Vol. 3. Washington, DC: World Bank (2015). p. 1221-146.

33. Biggar RJ, Chaturvedi AK, Goedert JJ, Engels EA. HIV/AIDS cancer match study. AIDS-related cancer and severity of immunosuppression in persons with AIDS. J Natl Cancer Inst. (2007) 99:962-72. doi: 10.1093/jnci/djm010 
34. Jolly PE, Mthethwa-Hleta S, Padilla LA, Pettis J, Winston S, Akinyemiju TF, et al. Screening, prevalence, and risk factors for cervical lesions among HIV positive and HIV negative women in Swaziland. BMC Public Health. (2017) 17:218. doi: 10.1186/s12889-017-4120-3

35. National Cancer Institute (NCI). Cancer in Children and Adolescents. National Cancer Institute. NCI (2017). Available online at: https://www.cancer. gov/types/childhood-cancers/child-adolescent-cancers-fact-sheet (accessed August 21, 2018).

36. Njuguna F, Martijn H, Langat S, Musimbi J, Muliro H, Skiles J, et al. Factors influencing time to diagnosis and treatment among pediatric oncology patients in Kenya. Pediatr Hematol Oncol. (2016) 33:186-99. doi: 10.3109/08880018.2016.1169566

37. Adebamowo CA, Casper C, Bhatia K, Mbulaiteye SM, Sasco AJ, Phipps W, et al. Challenges in the detection, prevention, and treatment of HIV-associated malignancies in low- and middle-income countries in Africa. J Acquir Immune Defic Syndr. (2014) 67(Suppl. 1):S17-26. doi: 10.1097/QAI.0000000000000255

38. Salaverria C, Rossell N, Hernandez A, Fuentes Alabi S, Vasquez R, Bonilla $\mathrm{M}$, et al. Interventions targeting absences increase adherence and reduce abandonment of childhood cancer treatment in El Salvador. Pediatr Blood Cancer. (2015) 62:1609-15. doi: 10.1002/pbc.25557

39. Brown BJ, Adeleye AO, Ibeh JN. A prospective study on the causes of delayed diagnosis of childhood cancer in Ibadan, Nigeria. Pediatr Hematol Oncol. (2015) 32:365-73. doi: 10.3109/08880018.2015.1040933

40. Buckle GC, Collins JP, Sumba PO, Nakalema B, Omenah D, Stiffler K, et al. Factors influencing time to diagnosis and initiation of treatment of endemic burkitt lymphoma among children in Uganda and western Kenya: a cross-sectional survey. Infect Agent Cancer. (2013) 8:36. doi: 10.1186/1750-9378-8-36

41. Arora RS, Eden T, Pizer B. The problem of treatment abandonment in children from developing countries with cancer. Pediatr Blood Cancer. (2007) 49:941-6. doi: 10.1002/pbc.21127

42. Fajardo-Gutiérrez A, Sandoval-Mex AM, Mejía-Aranguré JM, RendónMacías ME, Martínez-García M, Del C. Clinical and social factors that affect the time to diagnosis of Mexican children with cancer. Med Pediatr Oncol. (2002) 39:25-31. doi: 10.1002/mpo.10100

43. Brown BJ, James BO, Ajayi SO, Ogun OA, Oladokun RE. Factors influencing time to diagnosis of childhood cancer in Ibadan, Nigeria. Afr Health Sci. (2009) 9:247-53.

44. Haimi M, Nahum MP, Ben Arush MW. Delay in diagnosis of children with cancer: a retrospective study of 315 children. Pediatr Hematol Oncol. (2004) 21:37-48. doi: 10.1080/pho.21.1.37.48

45. Seden K, Back D, Khoo S. Antiretroviral drug interactions: often unrecognized, frequently unavoidable, sometimes unmanageable. $J$ Antimicrob Chemother. (2009) 64:5-8. doi: 10.1093/jac/dkp152

46. Caselli D, Klersy C, de Martino M, Gabiano C, Galli L, Tovo PA, et al. Human immunodeficiency virus-related cancer in children: incidence and treatment outcome-report of the Italian register. J Clin Oncol. (2000) 18:3854-61. doi: 10.1200/JCO.2000.18.22.3854

47. Israels T, Challinor J, Howard S, Arora H. Treating children with cancer worldwide-challenges and interventions. Pediatr Off J Am Acad Pediatr. (2015) 136:607-10. doi: 10.1542/peds.2015-0300

48. Israels $\mathrm{T}$, Ribeiro RC, Molyneux EM. Strategies to improve care for children with cancer in sub-saharan Africa. Eur J Cancer. (2010) 46:1960-6. doi: 10.1016/j.ejca.2010.03.027

49. Harif M, Barsaoui S, Benchekroun S, Bouhas R, Doumbé P, Khattab M, et al. Treatment of B-cell lymphoma with LMB modified protocols in Africareport of the French-African pediatric oncology group (GFAOP). Pediatr Blood Cancer. (2008) 50:1138-42. doi: 10.1002/pbc.21452

50. Israëls $\mathrm{T}$, Molyneux EM, Caron HN, Jamali M, Banda K, Bras $\mathrm{H}$, et al. Preoperative chemotherapy for patients with Wilms tumor in Malawi is feasible and efficacious. Pediatr Blood Cancer. (2009) 53:584-9. doi: $10.1002 /$ pbc. 22138

51. Hesseling P, Israels T, Harif M, Chantada G, Molyneux E. Pediatric oncology in developing countries. Practical recommendations for the management of children with endemic burkitt lymphoma (BL) in a resource limited setting. Pediatr Blood Cancer. (2013) 60:357-62. doi: 10.1002/pbc.24407

52. Molyneux E, Davidson A, Orem J, Hesseling P, Balagadde-Kambugu J, Githanga J, et al. The management of children with kaposi sarcoma in resource limited settings. Pediatr Blood Cancer. (2013) 60:538-42. doi: $10.1002 /$ pbc. 24408

53. Ssewamala FM, Ismayilova L. Integrating children's savings accounts in the care and support of orphaned adolescents in rural Uganda. Soc Serv Rev. (2009) 83:453-72. doi: 10.1086/605941

54. Sherraden M. Stakeholding: notes on a theory of welfare based on assets. Soc Serv Rev. (1990) 64:580-601. doi: 10.1086/603797

55. Schreiner M, Sherraden MW, Michael W. Can the Poor Save? Saving and Asset Building in Individual Development Accounts. New Brunswick, NJ: Transaction Publishers (2007). p. 372

56. Ssewamala FM. Optimizing the "demographic dividend" in young developing countries: the role of contractual savings and insurance for financing education. Int J Soc Welf. (2015) 24:248-62. doi: 10.1111/ijsw.12131

57. Schuler SR, Hashemi SM. Credit programs, women's empowerment, and contraceptive use in rural Bangladesh. Stud Fam Plann. 25:65-76. doi: $10.2307 / 2138085$

58. Vonderlack RM, Schreiner M. Women, microfinance, and savings: lessons and proposals. In: Development in Practice. Vol. 12 (2002). Available online at: http://www.microfinance.com/English/Papers/Women__Microfinance_ and__Savings.pdf (accessed August 21, 2018).

59. Ssewamala FM, Sperber E, Zimmerman JM, Karimli L. The potential of assetbased development strategies for poverty alleviation in sub-saharan Africa. Int J Soc Welf. (2010) 19:433-43. doi: 10.1111/j.1468-2397.2010.00738.x

60. Ssewamala FM, Wang JS-H, Karimli L, Nabunya P. Strengthening universal primary education in Uganda: the potential role of an asset-based development policy. Int J Educ Dev. (2011) 31:472-7. doi: 10.1016/j.ijedudev.2010.11.001

61. Bermudez LG, Ssewamala FM, Neilands TB, Lu L, Jennings L, Nakigozi $\mathrm{G}$, et al. Does economic strengthening improve viral suppression among adolescents living with HIV? Results from a cluster randomized trial in Uganda. AIDS Behav. (2018) 22:3763-72. doi: 10.1007/s10461-0182173-7

62. Ssewamala FM, Dvalishvili D, Mellins CA, Geng EH, Makumbi F, Neilands TB, et al. The long-term effects of a family based economic empowerment intervention (Subi+Adherence) on suppression of HIV viral loads among adolescents living with HIV in southern Uganda: Findings from 5-year cluster randomized trial. PLoS ONE. (2020) 15:e0228370. doi: 10.1371/journal.pone.0228370

63. McAllister J, Beardsworth G, Lavie E, MacRae K, Carr A. Financial stress is associated with reduced treatment adherence in HIVinfected adults in a resource-rich setting. HIV Med. (2013) 14:120-4. doi: 10.1111/j.1468-1293.2012.01034.x

64. Johnston SS, Juday T, Seekins D, Espindle D, Chu BC. Association between prescription cost sharing and adherence to initial combination antiretroviral therapy in commercially insured antiretroviral-naïve patients with HIV. J Manag Care Pharm. (2012) 18:129-45. doi: 10.18553/jmcp.2012. 18.2.129

65. Naik E, Casanas B, Pazare A, Wabale G, Sinnott J, Salihu H. Cost of treatment: the single biggest obstacle to HIV/AIDS treatment adherence in lower-middle class patients in Mumbai, India. Indian J Sex Transm Dis. (2009) 30:23-7. doi: 10.4103/0253-7184.55476

66. McCoy SI, Njau PF, Czaicki NL, Kadiyala S, Jewell NP, Dow WH, et al. Rationale and design of a randomized study of short-term food and cash assistance to improve adherence to antiretroviral therapy among food insecure HIV-infected adults in Tanzania. BMC Infect Dis. (2015) 28:490. doi: 10.1186/s12879-015-1186-3

Conflict of Interest: The authors declare that the research was conducted in the absence of any commercial or financial relationships that could be construed as a potential conflict of interest.

Copyright (c) 2020 Katumba, Sensoy Bahar, Johnson and Ssewamala. This is an open-access article distributed under the terms of the Creative Commons Attribution License (CC BY). The use, distribution or reproduction in other forums is permitted, provided the original author(s) and the copyright owner(s) are credited and that the original publication in this journal is cited, in accordance with accepted academic practice. No use, distribution or reproduction is permitted which does not comply with these terms. 


\section{ABBREVIATIONS, ACRONYMS, AND DEFINITIONS}

\begin{tabular}{ll}
$\begin{array}{l}\text { Abbreviation/ } \\
\text { Acronym }\end{array}$ & Definition \\
\hline YLWHIV & $\begin{array}{l}\text { Youth living with HIV/AIDS. Youth are defined as individuals } \\
\text { between the ages of } 0 \text { and } 24 \text { years. Therefore, this definition } \\
\text { includes younger children } 12 \text { years and under, teenagers and } \\
\text { young adults (18-24) }\end{array}$ \\
LMICs & $\begin{array}{l}\text { Low- and middle-income countries as defined by the World } \\
\text { LIC }\end{array}$ \\
WHO & $\begin{array}{l}\text { Wow-income countries as defined by the World Bank } \\
\text { ART }\end{array}$ \\
SSA & Antiretroviral therapy \\
HR & Sub-Saharan Africa \\
CSA & Hazard ratio \\
& Child Savings Account
\end{tabular}

